\title{
A Brief Overview on the Evolution of Drawing Machines
}

\author{
António Coelho ${ }^{(\bowtie)}(\mathbb{D})$, Pedro Branco (D), and João Martinho Moura (iD \\ University of Minho, Guimarães, Portugal \\ antonio.coelho@engagelab.org
}

\begin{abstract}
Through the pictorial narratives engraved on the walls of the caves during prehistory, we are sure that Humans used drawing to express feelings and communicate, long before inventing writing. In the same way that utensils were used to help him, he also used several utensils to draw.

In the middle of the twentieth century, with all the technological evolution, we saw machines that helped artists in drawing and others that are extensions of the artist.

In a project seeking the development of a robotic system capable of drawing autonomously we were faced with the question for how long artists have used drawing machines for their aid or even their extension? In this work, we present a collection of artworks that demonstrates the use of drawing machines throughout history in the last 500 years and how they are being adapted and reinvented according to the most current and also developing technology. At present there is a vast field of experimentation of these machines with Interfaces and Sensors and Intelligent Human-Computer Interaction.
\end{abstract}

Keywords: Drawing machines $\cdot$ Art machines ·

Autonomous cybernetic machines

\section{What Is a Drawing Machine?}

Pablo Garcia on his archive project [1] defines "Drawing machine" as any device/apparatus/mechanism/aid/instrument that draws or assists in the act of drawing.

While an apparently simple definition, it is in the expression "act of drawing" that the nature of this machines is revealed. The act of drawing refers to the "slow reveal, the gradual accumulation of contours and marks into an image". Photography and inkjet printers are certainly ways to mechanize the image-making process, but are not considered drawing machines. A drawing must be drawn.

"In this larger etymological context, producing a picture by making lines and marks - to draw-literally means to pull or drag a pencil or pen across a surface. It is a physical act. It is active pursuit, emphasis on pursuit. You chase, seek, and pursue the final drawing." [https://drawingmachines.org/about.php].

Also was defined by Watz [2] "Automated drawing machines are kinetic sculptures that make drawings, typically drawing on paper using pens, pencils, charcoal, or other traditional drawing implements." 


\subsection{Drawing Machines Characteristics}

Pablo Garcia on his archive project [1], characterizes drawing machines with three basic rules:

- A drawing machine can be an autonomous or semi-autonomous machine. This can be a set of human-powered gears or mechanical linkages that automatically generates an image through a machine-held stylus.

- A drawing machine must control - or help a user control - a stylus, a pointy object that leaves a mark or line on a surface when applied pressure: pen, quill, pencil, airbrush, or more recently capacitive tips for touchscreens.

- When used to draw from life, a drawing machine inserts itself into the stylus-handeye circuit. As the artist holds a stylus in her hand, whose movements are coordinated by eye, the drawing machine can guide the eye, or control the stylus, or augment the hand.

- The drawing machines discussed below will focus on apparatus that possess these three features. We will discuss mainly the drawing machines of the twenty and twenty-o century, while still providing some brief historical references throughout 500 years of drawing machines.

\section{Years of Drawing Machines}

\subsection{Renaissance - 19th Century}

Drawing changed in the early Renaissance thanks to Filippo Brunelleschi. Sometime around 1415, he developed a mathematical method for rendering realistic views known as linear perspective. This technique remained unpublished until Leon Battista Alberti produces On Painting in 1425. In it he not only describes at length the complex method for drawing a perspective, he outlines a shortcut in the last chapter [1].

\subsection{Automatons}

In 1774, one of the 3 automatons created for promotional purposes by the watchmaker Jaquet-Droz, "le dessinateur", are considered to be remote ascent of the computers in the line of machines that followed the path of the Pantographs, and assuming the role of intervening directly in the drawing. This drawing machine, designed in two years 1772-1774, has the peculiarity of moving the hand on the paper, attempting to mimic the human hand. This machine produces a spontaneous gesture, capable of producing dramatic and expressive drawings of a dog, Louis XV, a butterfly and a British couple.

Another Swiss watchmaker, Henri Maillardet (1745-1830), was a master of automatons, he created one who wrote in French and English, with cursive and decorated typography, drew a boat with a candle, a Chinese pagoda and cupid. The 
mechanical functions were armed in brass discs (their memory) and allowed these complex movements, actuated by well calibrated and precise mechanisms (Fig. 1).
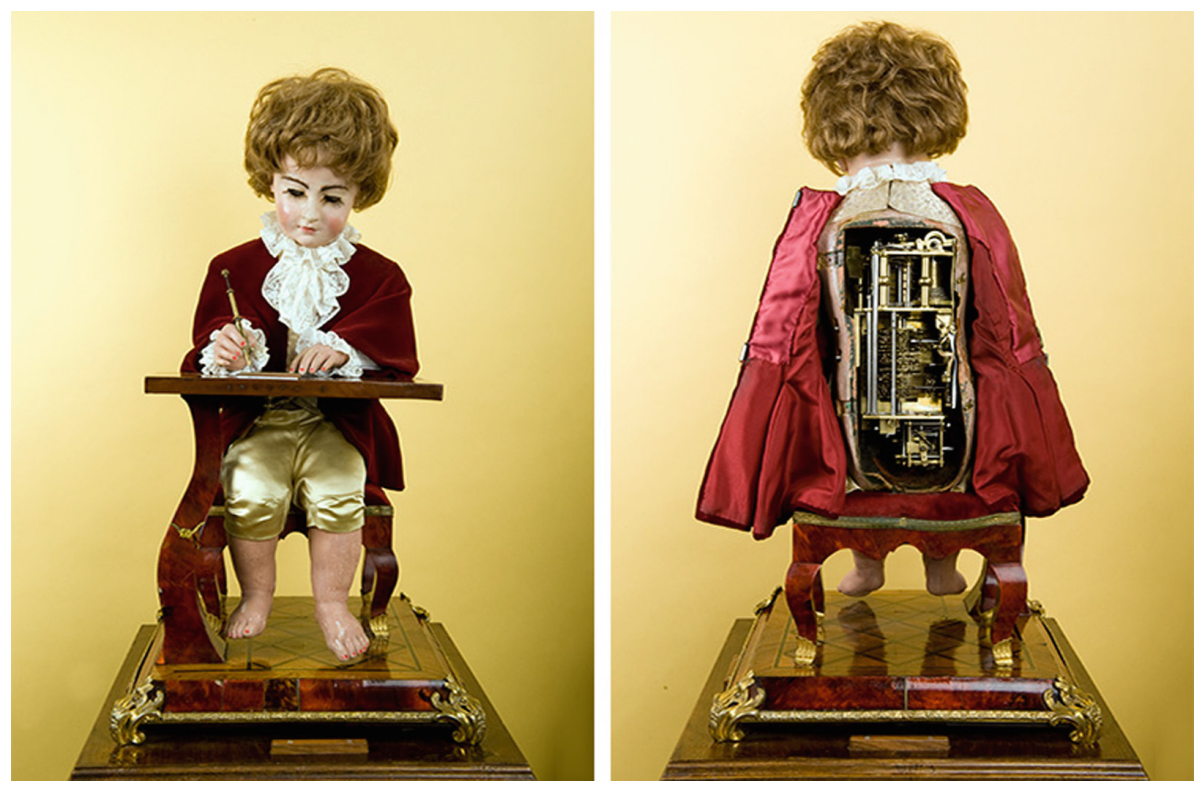

Fig. 1. "Le Dessinateur”, Automates Jaquet-Droz, 1774

\section{20th Century}

In the 20th century, the technological advances saw an unprecedented fast pace development, which led to the production of many machines, and experimentation with new machines drawing came by. The invention of television and the emergence and use of the computer, associated with theories of science, came to revolutionize the form of artistic production. Gradually the drawing machines have gained their place, also with applications in the industry. "As collage technique replaced oil paint, the cathoderay tube will replace the canvas" [3].

In the middle of the 20th century, Jean Tinguely's became famous for his kinetic machines. Some of his mechanisms were drawing machines [4]. With the emergence of Kinetic Art, we have the appearance of the Desmond Paul Henry drawing machines, [5] which used modified bombsight analog computers, that calculated the trajectories of the bombs dropped from planes. These machines created complex, curvilinear and repetitive line drawings, visually similar to parables, which were either left untouched as completed drawings or embellished by the artist's hand. 


\subsection{Cybernetic Art, Robot Art, Computational Art}

The origin and meaning of the term "cybernetics" was originally coined by French mathematician and physicist André Marie Ampère (1775-1836) in reference to political science [6]. In the 1940s, the American mathematician Norbert Wiener, generally recognized as the founder of cybernetic science, retrieves the term of the Greek word "kubernetes" (helmsman, who drives the boat) "Cybernetics: or control and communication in the animal and the machine" (1948). According to Wiener, Cybernetics has developed a scientific method that uses probability theory to regulate the transmission and feedback of information as a means of controlling and automating the behavior of mechanical and biological systems. Cybernetics had a decisive impact on art. This impact was in itself mediated by the aesthetic context that coincided with the emergence of scientific theory in the late 1940 s and by the complementarity between cybernetics and central tendencies of experimental art of the twentieth century. The Art of Post-World War II, had an emphasis on the concepts of process, system, environment and public participation, cybernetics was able to gain artistic value as a theoretical model to articulate the systematic relationships and processes between (loops and feedback), including artist, art, public and environment. In this way, cybernetic art is part of contemporary art, which has as reference all the scientific theory of cybernetics, where the feedback involved in the process takes precedence over traditional aesthetic and material interests. Nicolas Schöffer (1956) is seen as the creator of the first work of art with the CYSP sculpture (cybernetics and SPatiodynamic) that explicitly uses cybernetic features. Edward A. Shanken, an art historian, has written on the history of art and cybernetics in essays, including "Cybernetics and Art: Cultural Convergence" in the 1960s and "Telematics Embrace, visionary theories of art, technology and consciousness [7], Roy Ascott” (2003), which traces Ascott's work on cybernetic art to telematic art computers as its medium, pioneer to net.arte) [8].

The 1960s produced a lineage of "Cyborg" art, which was very concerned about shared circuits within and between the living and the technological, with works by Edward Ihnatowicz, the cybernetic Gordon Pask and the kinetic animists of Robert Breer and Jean Tinguely.

\subsection{Robotic Art}

A landmark in robotic art Robot K-456 (1964) by Num Jun Paik and Shuya Abe's, was a 20-channel anthropomorphic robot controlled by radio. Its name derives from Mozart's piano concerto (Köchel's Catalog 456). The robot first appeared in Robot Opera, Judson Hal and on the streets, at the Second Annual New York Avant-Garde Festival. The K456 is now in the private collection of the Hauser and Wirth in Zurich [9].

\subsection{SQUAT}

SQUAT a Cybernetic System, created by Tom Shanon in 1966, interlinked a robotic sculpture with a living plant, in the one that was the beginning of the interactivity in the 
cybernetic art. In this interaction, the electrical potential of the human body was used to connect an organic switch. When touched by users, the plant was energetically enlarged and directed to the motors of the sculpture that provided movement. The Human-Plant interaction, in SQUAT, made the sculpture retract, and in oscillating movements and sonorous humming, raised the 3 legs and arms. The return to the initial position was restored if the plant was to be touched again.

\subsection{Edward Ihnatowicz}

Edward Ihnatowicz study at the Ruskin School of Drawing and Fine Art, University of Oxford. He developed a computer-controlled biomorphic robotic creature, which he named The Senster.

The Senster, had an articulated system, based on the claw of the lobster, but with a larger scale. It was about 15 feet long and 8 feet high, integrated with six electrohydraulic servo-motors. Sensory microphones and motion detectors were incorporated into his pseudo-head, with which he provided sensory information, which was processed in a real-time Philips "microcomputer" which had a reaction capacity, a delay of 1 to $2 \mathrm{~s}$. He had an apparent, sensual and intelligent behavior, which gave him a great attractiveness. If in SQUAT, the tactile participation was crucial, in The Senster, the main one was the voice and proximity of the users. He was exhibited at Evolun, the Philips showcase in the Netherlands since 1970 and was dismantled in 1974 [10].

The emergence of Sketchpad, the first computational software and the appearance of the Computational art in 1963, where the $3 \mathrm{~N}$, composed by Frieder Nake, George Nees and Noll, realized their first graphic experiences, which resulted in an aesthetic of geometric forms, standardization, repetition and sequential variation, use of line and points, abstraction, bidimensionality [11]. It is at this latest junction of the machines that they draw in an automated way but without the interference of the artist with programing, and of the computational program that we nowadays watch to Robots that draw of random form.

\subsection{Harold Cohen}

Harold Cohen was a British artist who was best known for creating AARON, at University of California, San Diego, in 1968, a new robot type with a computer system that autonomously produces Art. Harold Cohen, continuously for over 30 years of research at the Stanford University Artificial Intelligence Laboratory since 1973, developed and "teached" AARON to Draw and later to Paint. AARON exhibited at Tate Gallery (London), the Stedelijk Museum (Amsterdam) at the Brooklyn Museum in New York, at the Museum of Modern Art of San Francisco, and all over the world. Harold Cohen, has a permanent exhibition dedicated to his work at the Boston Computer Museum [12] (Fig. 2). 


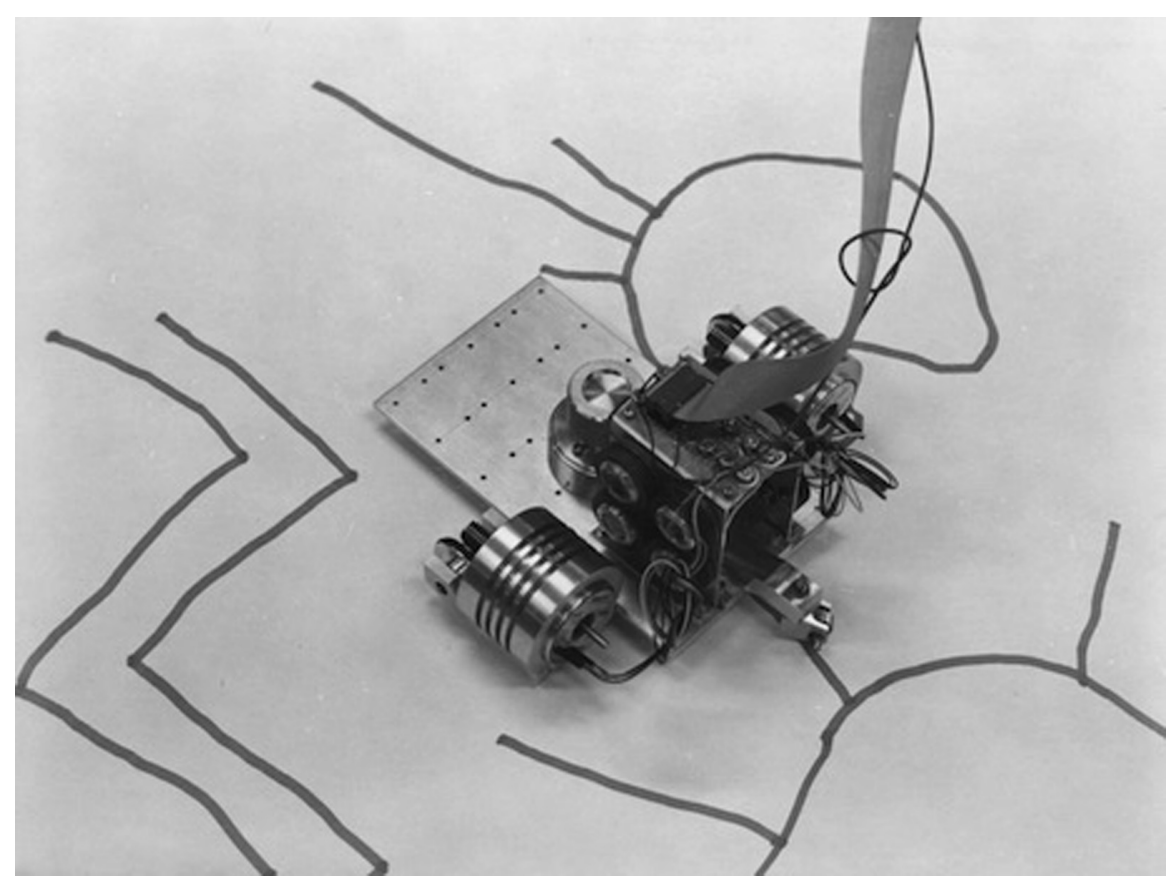

Fig. 2. Harold Cohen, AARON, at University of California, San Diego

\section{Machines as Extension of the Artist}

Telematics combines telepresence with computers and was an important field of artistic exploration after the emergence of the world wide web. The term itself was coined in 1978 and Roy Ascott was the first theoretician to apply it to art in 1979. Finally, telerobotics combines telematics with robotic structures, occurring whenever it can be present through incorporation into a robot [13].

\subsection{1st Century}

In this century there are a multitude of drawing machines, of every kind, Vibrobots ${ }^{1}$ are still around. At the moment, the position of machines in the field of the arts is still under discussion. Are these machines an auxiliary mechanism of the artists, or are them in facts the artists? Some of the most relevant artists in the area of Robotic Art, are using them as extensions of themselves.

\footnotetext{
${ }^{1}$ Little Robots powered by vibrating motors.
} 


\subsection{Angela Bulloch}

Angela Bulloch who works mainly with installations and sound, like her installation, "Constructostrato Drawing Machine Red".

\subsection{Rebecca Horn}

Rebecca Horn works with different types of media, such as video, installation, performance, sculpture [14]. "The Painting Machine".

\subsection{Leonel Moura}

Leonel Moura a conceptual artist, whose initial work in photography and video, changed, in the late 90s, to robotic art and Artificial Intelligence [15]. "Robotarium", a robot zoo, and many painting robots, of which the Robotic Action Painter (RAP) was exhibited as a permanent installation at the American Museum of Natural History in New York. Also featured is a robot that makes drawings based on emergency and stigma, and decides when the work is ready and signs, Adapted piece R.U.R. (Rossum's Universal Robots) by Karel Capek, Leonel Moura, is the author of several books dedicated to Art and Science.

\subsection{Hector}

Hector was developed in 2002 by Jurg Lehni and Uli Franke, is a minimalist installation of a drawing machine. It consists of 2 step-motors, aligned horizontally from where it suspends. It consists of electric motors, a spray can holder, toothed belts, cables, a strong battery and a circuit board that is connected to a laptop and controls a machine. Hektor is controlled directly from within Adobe Illustrator ${ }^{\mathrm{TM}}$, the spray-can follows the paths of the vector graphic and those scattered on the wall. The goal was to create a tool with his own aesthetic. It was intended as a reaction to a monoculture with no design, by the use of its computer systems and the unique applications and techniques - all connected mainly in vector graphics - by the majority of the designers of the world. Hektor follows vector paths as the hand follows a line as he draws. In addition, with a spray-can Hektor uses a tool that was made to be used by the human hand. Combined with a fragility of installation, this aspect confers a less accurate but somehow poetic quality system. Ambitious on purpose, Hektor unifies this quality with a purity of technological perfection (Fig. 3).

\subsection{Sandy Noble's}

Sandy Noble's passion for machines and mechanisms led him to develop a drawing machine, called Polargraph, which he uses to produce drawings. A coordinate system with double triangulation. The angle of each cable is controlled by the length of both cables, using stepmotors, instead of specifying the angle and distance as in a true polar coordinate. The drawing is done, with the scratcher, placed in a gondola, at the apex of this triangle, on a sheet of paper. This machine is available on his website, with the construction manual. 


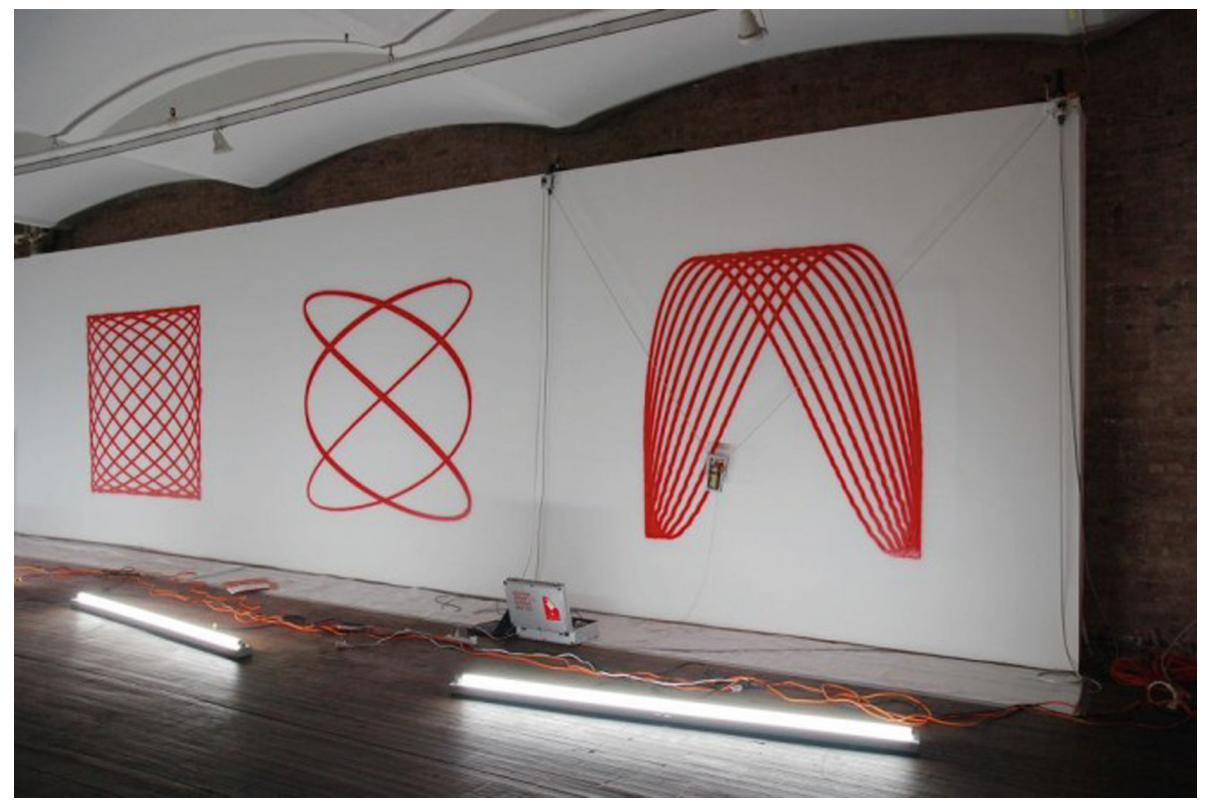

Fig. 3. Hector, Jurg Lehni

\subsection{Sam van Doorn}

Sam van Doorn created, the STYN. He deconstructed a pinball machine and rebuilt it as a drawing machine. The print is placed on top of the machine, based on this grid the user can structure his field of play as he wants, when placing balls in the machine, they create an unforeseeable pattern, depending on the interaction between the user and the machine.

\subsection{Paul the Robot}

Paul the Robot created by Patrick Tresset, a French artist/scientist based in London at Goldsmith College, University. It uses the term "clumsy robotics" to create autonomous cybernetic entities that are playful projections of the artist [16].

In this sense, Paul the robot, is his more mediatic and complex project from the point of view of the expressiveness of the drawing. Paul, is a robotic installation that produces portrait drawings through direct observation of people. Paul, does not have high-level knowledge of human face structures (such as mouth, nose, eyes), nor the ability to learn skills based on experience as a human would. However, Paul is able to draw using the expressive equivalent of an artist based on a number of processes that mimic drawing and technique skills, which together form a design cycle. Finally, the designs produced by Paul have been considered of interest by fine art professionals at recent international art fairs and exhibitions, as well as by the general public. 
One of the designs is in the Victoria and Albert museum collection. It is to be considered that a series of factors, of mimesis of human gesture, on the part of Paul, can be responsible for the qualities of the drawings produced (Fig. 4).

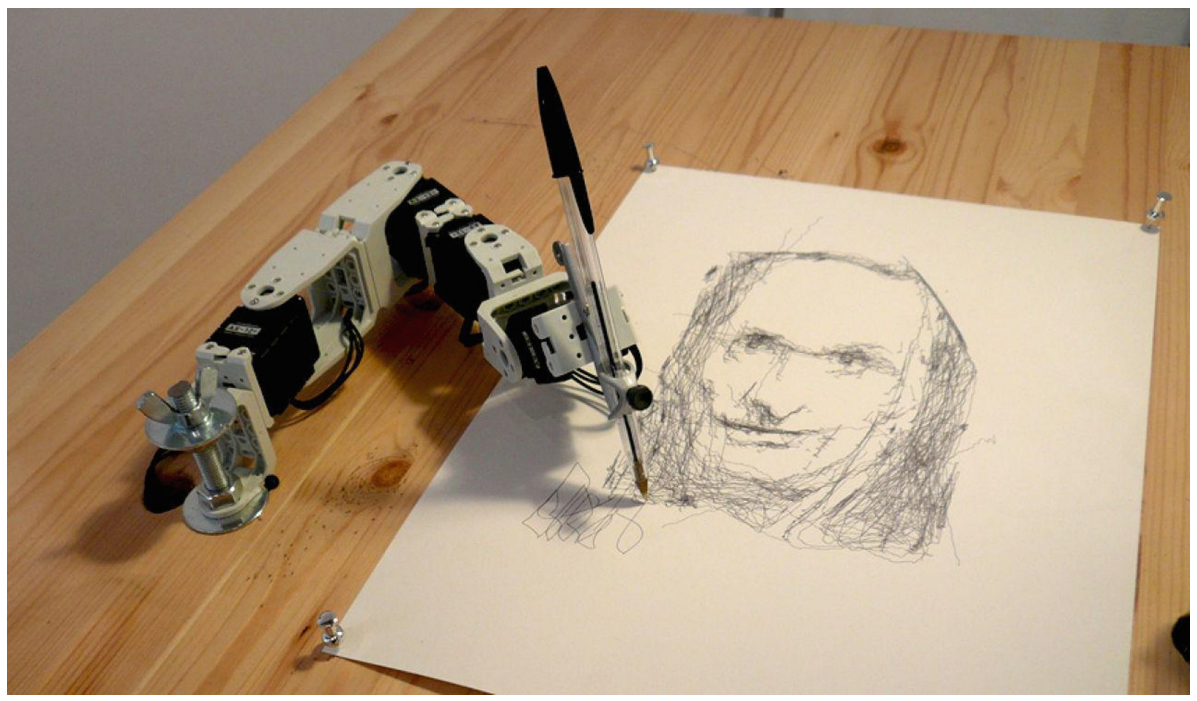

Fig. 4. Patrick Tresset, Paul the robot.

\subsection{Line-Us}

Line-us is a new small London company, founded by Durrell Bishop and Rob Poll who have designed, developed and manufactured a small nicely-designed portable internet connected robot drawing arm creative tool, that was originally inspired by Tim Lewis's mechanical drawing machines. "We wanted to see if it was possible to make a drawing robot using very simple and inexpensive components, and if we could whether it could produce interesting drawings. We were also interested to see what possibilities were enabled by connecting a drawing robot to the internet." Rob Poll. Line-us uses three simple RC type Servos, two for the arms and one attached to a cam to lift the pen, and a very low cost WiFi module that's more commonly used in products like smart plugs. The WiFi module turned out to be surprisingly powerful and we've been able to add features like the ability for the Line-us to 'follow' a remote sketchbook over the internet, and flash its light when a new drawing has been added. Pressing the button will draw the drawing, opening up the use of Line-us as a fun communication tool.

Line-us has an App, and the Line-us Cloud allow users to store, share and publish their Sketches over the internet but Line-us also has programming APIs that allow users to write their own code to control Line-us. We've already seen some interesting uses, and people have been controlling Line-us from a wide range of programming languages (and we've just added Scratch). Rob Poll (Fig. 5). 


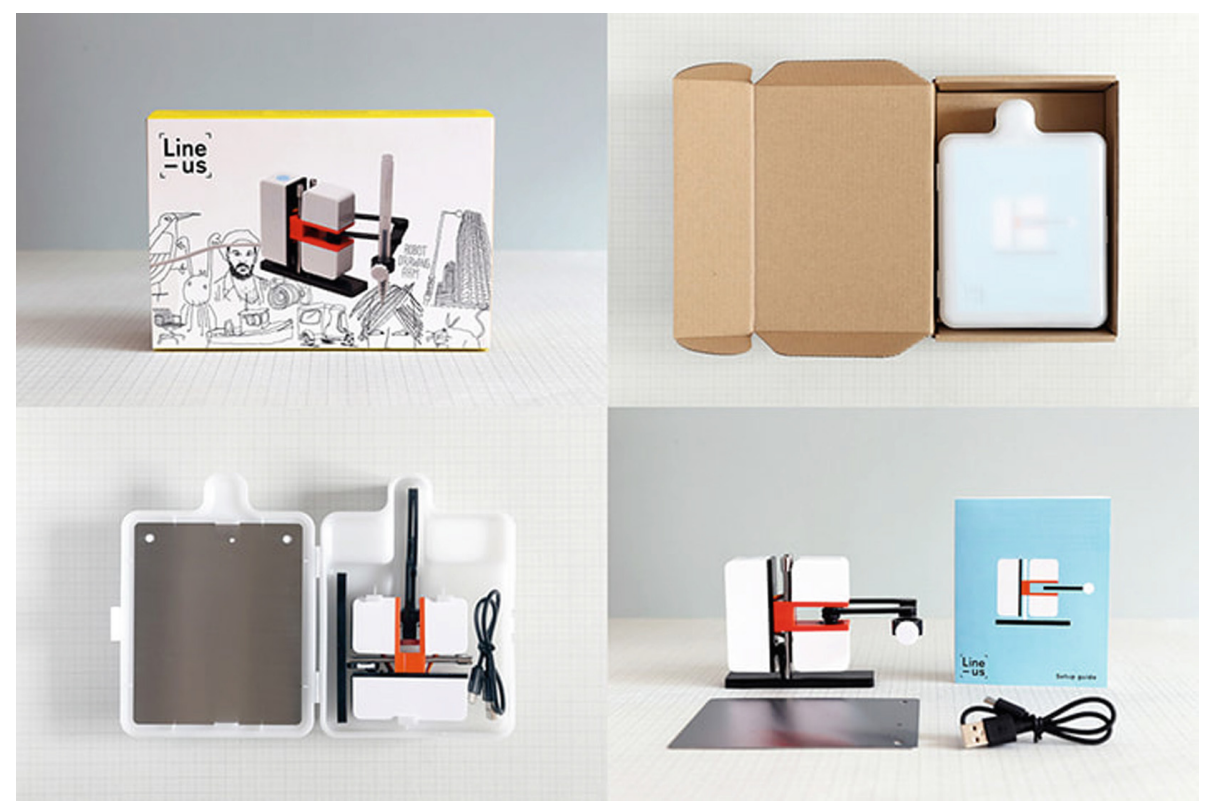

Fig. 5. Line-Us, drawing machine

\section{Conclusion}

Human being has always felt the need to increase their technical abilities. Throughout human history, crossing various civilizations there were mechanisms to aid the drawing. The Book of Knowledge of Ingenious Mechanical by Ibn al-Razzaz al-Jazari [17] from 1206 identifies a great variety of autonomous mechanisms. The great change, we could almost call it the Golden Age of the Drawing Machines, was, as with all the arts, in the Renaissance period. New techniques for the representation of reality were conceived, new aid methods such as the "Alberti Veil" or the Lucida Camera, and drawing machines, which functioned as an extension of the artist, such as the Pantographs, which had the ability to simultaneously enlarge the drawing. The emergence of quite complex autonomous mechanisms, which had the ability to draw, arose by the hand of Swiss watchers, such as Jaquet-Droz and Mailleret. In the twentieth century, the emergence of Jean Tinguely's machines were a precursor to the cybernetic machines of Desmond Paul Henry. The beginning of computer graphics in the 60s, gave rise to the programming of more autonomous machines, and so appeared the first cybernetic sculptures and robot art. Generativism was extremely influential throughout the second half of the 20th century and in the first decade of the 21st century, and still is today. The machines produced real-time art, replacing artists, as Angela Bulloch and Rebecca Horn, systems, like the device Line-us, offer a vast field for artistic experimentation.

A recent paper, "A Neural Representation of Sketch Drawings" [18] presents a generative recurrent neural network capable of producing sketches of common objects, 
with the goal of training a machine to draw and generalize abstract concepts in a manner similar to humans. Emerging systems that are driven by machine learning and AI systems, capable of perceiving and evaluating their outputs, open up new fields for the creation of drawing machines.

"You might not realise it, but you interact with AIs every day. They route your cell phone calls, curate your news feeds, approve your credit card transactions, and help doctors diagnose disease. Soon they will drive your car." [19] We can say soon they will draw for you!

\section{References}

1. Drawing Machines. https://drawingmachines.org/. Accessed 14 July 2018

2. Watz, M.: Drawing Machines 1-12 (2004)

3. Rosenberg, D.: Screendance: Inscribing the Ephemeral Image. Oxford University Press, Oxford (2012)

4. Pardey, A.: The Jean Tinguely Museum: caring for machine sculptures. In: Modern Art: Who Cares?: An Interdisciplinary Research Project and An International Symposium on the Conservation of Modern and Contemporary Art (2005)

5. O'Hanrahan, E.: The contribution of Desmond Paul Henry (1921-2004) to twentieth-century computer art. Leonardo 51(2), 156-162 (2018)

6. Williams, L.P.: André-Marie Ampère. Scientific American, vol. 260, pp. 90-97. Scientific American, a division of Nature America, Inc. (1989)

7. Shanken, E.A.: Art in the information age: cybernetics, software, telematics, and the conceptual contributions of art and technology to art history and theory. ProQuest Dissertations Theses (2001)

8. Wanner, A.: The robot quartet: a drawing installation. Comput. Commun. Aesthet. X xCoAx2013 (2013)

9. Kac, E.: The origin and development of robotic art. Converg. Int. J. Res. New Media Technol. 7(1), 76-86 (2001)

10. Dixon, S.: Digital Performance: A History of New Media in Theater, Dance, Performance Art, and Installation. MIT Press, Cambridge (2007)

11. Dreher, T.: IASLonline NetArt: History of Computer Art III.2 Computer Graphics (2011). http://iasl.uni-muenchen.de/links/GCA-III.2e.html. Accessed 02 July 2018

12. Cohen, J.M., Hughes, J.F., Zeleznik, R.C.: Harold: a world made of drawings. In: NPAR 2000, pp. 83-90 (2000)

13. Candy, L., Edmonds, E.: Explorations in Art and Technology. Springer, London (2002). https://doi.org/10.1007/978-1-4471-0197-0

14. A. M. dos S. P. Associação Portuguesa de Estudos Anglo-Americanos, Op. cit. (Lisboa), vol. 2nd Series, no. 2. APEAA (2013)

15. Moura, L.: A New Kind of Art: The Robotic Action Painter (2007)

16. Tresset, P., Fol Leymarie, F.: Portrait drawing by Paul the robot. Comput. Graph. 37(5), 348-363 (2013)

17. Nadarajan, G.: Islamic Automation: Al-Jazari's Book of Knowledge of Ingenious Mechanical Devices | Muslim Heritage. http://www.muslimheritage.com/article/islamic-automation-aljazari's-book-knowledge-ingenious-mechanical-devices. Accessed 03 July 2018

18. Ha, D., Eck, D.: A Neural Representation of Sketch Drawings, April 2017

19. Heaven, D.: Machines that think: everything you need to know about the coming age of artificial intelligence (2017) 